\title{
Peritoneal Fluid Analysis of the Newborn Calves with Intestinal Atresia - a Clinical Approach
}

\author{
Hakan Salci', Serkan Catik², Emsal Sinem Ozdemir Salci ${ }^{3}$ \& Cuneyt Ozakin ${ }^{4}$
}

\begin{abstract}
Background: Anomalies and fetal problems are encountered in all animals. Intestinal atresia is a congenital anomaly of both humans and animals. Intestinal atresia has four morphological types, and they can be observed in jejunum, ileum, cecum, colon, rectum and anus (type I: mucosal atresia, type II: atretic ends separated by fibrous cord, type III: atretic ends separated by a "V" shaped mesenteric gap or atretic end coil like an "apple peel", type IV: multiple atresia). In calves, it is also commonly encountered; it is still a question to be replied about the exact prognosis of the patients with intestinal atresia. Thus, the main objective of the present study was to evaluate peritoneal fluid analysis results of calves with intestinal atresia.

Materials, Methods \& Results: Twenty-two calves were presented with abdominal distension and lack of defecation. Clinical and radiological findings pointed out the intestinal atresia. Blood samples were collected for routine hematological and serum total protein (TP) analysis. Peritoneal fluids were aspirated with sterile technique from the caudal abdomen, and biochemical features, cell contents and microbiological cultures of the peritoneal fluids were analyzed. Following to preoperative, surgical and necropsy findings, intestinal atresia were diagnosed as type II, III and IV in calves. Neutrophilic leukocytosis was observed in calves with type IV intestinal atresia. Red blood cells and platelet counts were determined in the peritoneal fluids. TP and density values of the peritoneal fluid were high in all cases. These results pointed the presence of the acute infection and peritonitis. Statistical comparison of each parameter showed that there was no significant difference between the types of intestinal atresia. Microbiologically, fecal origin bacteria were cultured in 12 calves.

Discussion: In general, four types of intestinal atresia are encountered in calves, and all types are fatal pathologies; thus, surgery should urgently be planned as soon as diagnostic work-ups are completed after birth. Peritoneal fluid analysis is a useful diagnostic choice because changes in the peritoneal fluid parameters help to diagnosis of the intra-abdominal pathology. Intestinal atresia as more common anomaly in Holstein, Jersey and Montafon breed calves. In animals with intestinal atresia, surgical treatment is not usually recommended due to economic reasons and small chance of postoperative success. Long-term survival rate of surgically treated animals depends on the type of intestinal atresia and applied surgical technique. Atresia recti and ani may occur simultaneously with atresia coli, and all atresias (atresia coli, ani, recti or ani et recti) can be successfully treated by surgery. Continuous distention of the large intestinal segments leads to ischemia, necrosis, peritonitis and bowel perforation. Peritoneal fluid analysis should include the classic parameters for diagnosis, but these analyses are often insufficient to identify the etiology or pathogenesis of the disease. An increase in total WBC count and percentage of the neutrophil cells in the peritoneal fluid indicate the acute infectious origin inflammation. Additional parameters in the peritoneal fluid analysis have been established to improve diagnostic precision and specific information. Presence or absence of the bacteria in the peritoneal fluid samples is important to characterize the transudate and exudate. Changings in the peritoneal fluid values does not related to type of the intestinal atresia in calves.
\end{abstract}

Keywords: calf, intestinal atresia, peritoneal fluid analysis. 


\section{INTRODUCTION}

Anomalies and fetal problems are encountered in all animals [2]. The environmental or individual factors as well as genetic predispositions (chromosomal or autosomal dominance) are responsible for these anomalies [2,3]. Furthermore, diagnosis of pregnancy by rectal palpation between 36 to 42 days of gestation is informed as another cause of the intestinal anomalies in calves $[6,12]$. In the embryonic life, gastrointestinal tracts develop from a ventrally located tube, which consist of endoderm and surround with splanchnic mesoderm. This tube differentiates to small and large bowel and if the blood supply of the tube interrupts during organogenesis period, the intestinal anomalies occur [1].

Intestinal atresia is a lethal congenital anomaly. It has incomplete and/or discontinuous gastrointestinal tracts resulted from luminal closure of the intestines and abnormal evolution of the gut segments $[3,6,12]$. Intestinal atresia has four morphological types, and they can be observed in jejunum, ileum, cecum, colon, rectum and anus (type I: mucosal atresia, type II: atretic ends separated by fibrous cord, type III: atretic ends separated by a "V" shaped mesenteric gap or atretic end coil like an "apple peel", type IV: multiple atresia) $[3,6]$. The clinical signs of calves with intestinal atresia may be evidently seen following to parturition, and the typical clinical signs are depression, anorexia and abdominal distension [6,12].

Diagnostic imaging techniques are used to confirm the presumptive diagnosis of the intestinal atresia [6]. Before surgical anastomosis of the discontinuing bowel segments or colostomy [6], prognostic evaluation should be performed for the successful surgical results [9]. Peritoneal fluids determine the healthy status of the peritoneum $[9,10,13]$; therefore, peritoneal fluid analysis is a useful approach to diagnosis of the peritoneal diseases [5,8-10]. Cellularity and protein characteristics of the peritoneal fluids exhibit the inflammatory changes, which result from the peritoneal disease $[8,10]$. In veterinary medicine, peritoneal fluid analysis is applied to diagnostic investigations and also to estimate the prognosis in many species $[5,9]$.

Thus, the aim of the present study was to investigate peritoneal fluid analysis results of calves with different type intestinal atresia.

\section{MATERIALS AND METHODS}

\section{Animals}

Totally 22 calves (different breed, sex and in day-old) presented with the complaint of abdominal distension and absence of the defecation to Uludag University, Faculty of Veterinary Medicine, Large Animal Clinics in the period between January 2011 and February 2014. The retrospective evaluations of the medical records of these calves were performed in this study.

\section{Diagnostic approaches}

Physical examinations (pulsation, respiration, body temperature, dehydration status, sucking reflex, capillary filling time) and clinical work-ups (inspection, palpation, and also anal and per-rectal examinations in calve with atresia coli) of the calves were performed to detect the gastrointestinal system pathology. Radiological and ultrasonographical examinations were carried out to describe the abnormality. After these evaluations, intestinal atresias were diagnosed; however, the types of the atresias were determined following to either surgical intentions or necropsy.

\section{Sampling}

Venous blood samples were taken from V. jugularis to the sterile vacutainer blood collection tubes ( 3 $\mathrm{mL}$ sodium EDTA) using 20 no vacutainer needle and holder. Before peritoneal fluid sampling, the calves were positioned to lateral recumbence and the upper leg was holt dorso-caudally to facilitate the manipulation as described previously $[5,13]$. Hair of the caudal abdominal region was clipped and a $10 \%$ povidone-iodine solution (Batticon $\left.{ }^{\circledR}\right)^{1}$ was applied for antisepsis. Peritoneal fluids were taken by ultrasound-guided abdominocentesis. Peritoneal fluid was aspirated with 20 no vacutainer needle to the sterile vacuum tubes. All samples were taken to the laboratories for analysis within $30 \mathrm{~min}$.

\section{Blood and peritoneal fluid analysis}

Hematological analysis included white blood cell (WBC), lymphocyte (Lym), monocyte (Mon), neutrophil (Neu) and serum total protein (TP) concentration. The parameters of WBC, Lym, Mon, Neu, red blood cell (RBC), hemoglobin (Hgb), hematocrit (Hct), platelet (Plt), total protein (TP) and density (D) were analyzed in the peritoneal fluids. In addition, peritoneal fluids were microbiologically investigated to determine the possible microorganism. 
The cell contents of the blood and peritoneal fluids were analyzed by an automatic analyzer (Vetscan HM5 $)^{2}$, and TP and D values were measured by a hand refractometer ${ }^{3}$.

\section{Culture}

Samples were incubated to $5 \%$ sheep blood agar4, Eosin Methylene-blue agar4 and Thioglycollate broth medium ${ }^{4}$ at $35^{\circ} \mathrm{C}$ under atmospheric conditions.

The available panels (NMIC and PMIC) ${ }^{5}$ for identification were selected after Gram staining of the colonies determined following evaluations at the 24 , 48 and $72 \mathrm{nd} \mathrm{h}$ in $5 \%$ sheep blood and EMB agars. The Phoenix 100 ID system (NMIC and PMIC®) ${ }^{5}$ was used to identify the bacteria.

\section{Surgery and follow-ups}

Surgically, a conventional colostomy technique was carried out as reported previously [6] on the ventral abdominal site by the same surgical team under general anesthesia. Ketamine $\mathrm{HCl}$ (Alfamine ${ }^{\circledR}$ - $4 \mathrm{mg} / \mathrm{kg}$ ) ${ }^{6}$ was intramuscularly administered as anesthetic agent after intramuscular injection of xylasine $\mathrm{HCl}$ (Alfazine - 0.01 $\mathrm{mg} / \mathrm{kg})^{6}$. Two times a day intravenous $1.1 \mathrm{mg} / \mathrm{kg}$ flunixine meglumine ${ }^{7}$ and one time per day intramuscular total $20 \mathrm{~mL}$ benzyl penicillin chemisol-streptomycin sulphate (Clemipen-Strep $)^{8}$ combination were administered as analgesic and antibiotic drugs for 5 days. The antibiotic usage was also repeated with large-scale different agents at early postoperative period considering to culture results (gram positive and negative).

With the permission of the owners, the necropsy was performed to diagnose the intestinal pathology in cases euthanized or died.

\section{Statistical analysis}

The average and standard deviations of the hematological and peritoneal fluid analysis results were calculated to simplify the comparison of the parameters. After grouping of the cases according to types of intestinal atresia, and hematological and peritoneal fluid parameters were compared using One-way ANOVA. All these statistical analysis were performed on a computer program (SPSS 23.0.) .

\section{RESULTS}

Intestinal atresia was diagnosed in Holstein ( $\mathrm{n}$ $=21)$ and Jersey $(n=1)$ breed calves (Table 1). Lateral and ventro-dorsal abdominal radiographs of the calves showed the fluid and/or gas-filled intestinal segments (Figure 1). The agenesis part of the intestines was not clearly detected by abdominal ultrasonography. There were only cranio-caudal fluctuating movements of the intestinal contents as well as gas-filling segments caused the reverberation artifacts. In addition, different amount of free peritoneal fluid was determined in the peritoneal space.

Peritoneal fluid samples (about $3 \mathrm{~mL}$ ) of the calves were taken from the peritoneal space. They were yellowish color and had mild to moderate cloudy appearance. In addition, the samples had no blood content but fibrin formation was determined after waiting a few minutes in holding up position (Figure 2).



Figure 1. The lateral abdominal radiograph of a case with atresia coli, this view shows the gas filled intestinal segments.

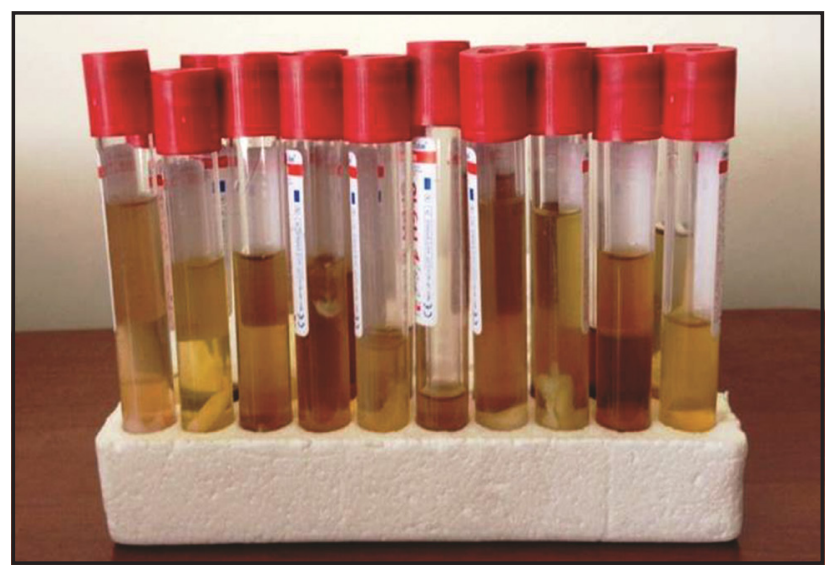

Figure 2. Peritoneal fluids collected from the calves in the study.

Outcomes of the calves are given in Table 1. A conventional colostomy technique was performed in fourteen calves $(n=14)$. These calves were discharged 
following to surgery. The owners of the cases informed their early time postoperative results that there were no mortality and the calves were healthy.

Following to diagnoses, four calves $(n=4)$ were euthanized with thiopental $\mathrm{Na}$, because their owners did not permit to surgery. Physical findings of two calves $(n=2)$ were poor, and they died due to supportive therapy. Necropsy was performed to these calves. One calf $(n=1)$ died intraoperatively due to sudden onset respiratory arrest. A calf was died early postoperative period due to colostomy site dehiscence, which was considered as a surgical failure.

Necropsy of the euthanized calves $(n=4)$ revealed type II $(n=2)$ and type IV $(n=2)$ atresias. Distal intestinal segments of descending colon were continuing with a fibrous cord in calves with type II. In type IV atresia, absence of the cecum, a fibrous cord formation of ascending and descending colon was clearly determined.

According to the results informed above, type II $(\mathrm{n}=8)$ (Figure 3$)$, type III $(\mathrm{n}=5)$ and type IV ( $\mathrm{n}$ =9) atresias were diagnosed in calves. Type I atresia was not encountered (Table 1). The mortality rate of the calves included in the study was $36 \%$.

\section{Hematological results}

The blood samples analyze results are detailed in Table 2. WBC values were high in 9/22 calves (40\%) and there was neutrophilia in 16/22 (72\%). TP values of 5 / 22 calves (\%22) were high and leukopenia was the other findings in 2 / 22 calves (1\%).

\section{Peritoneal fluid analysis results}

Peritoneal fluid analysis results of the calves are given in Table 3. WBC value was high only in a calf (4\%), and Lym, Mon and Neu values of the calves were within reference ranges. In contrast to appearance of the samples, RBC was determined in the peritoneal fluids of 16 calves (72\%). Moreover, Hgb, Hct and Plt were also determined in the peritoneal fluids. TP and $D$ values were higher in all calves.

\section{Microbiological analysis results}

Bacteria were cultured in 12 peritoneal fluid samples of the calves (54\%). All these bacteria (Escherichia coli, Enterococcus casseliflavus/gasllinarum, Staphylococcus lugdunensis, Enterococcus faecium, Proteus vulgaris, Citrobacter braakii, Staphylococcus capitis subsp. ureolyticus, Kocuria rosea, Proteus spp., Staphylococcus warneri and Proteus mirabilis) were recognized as being of fecal origin (Table 3).

\section{Statistical analysis results}

According to types of the intestinal atresia, the mean and standard deviation values of the hematological and peritoneal fluid analysis results and their $P$ values were given in Table 4. There was no significant difference between the types of the intestinal atresia.

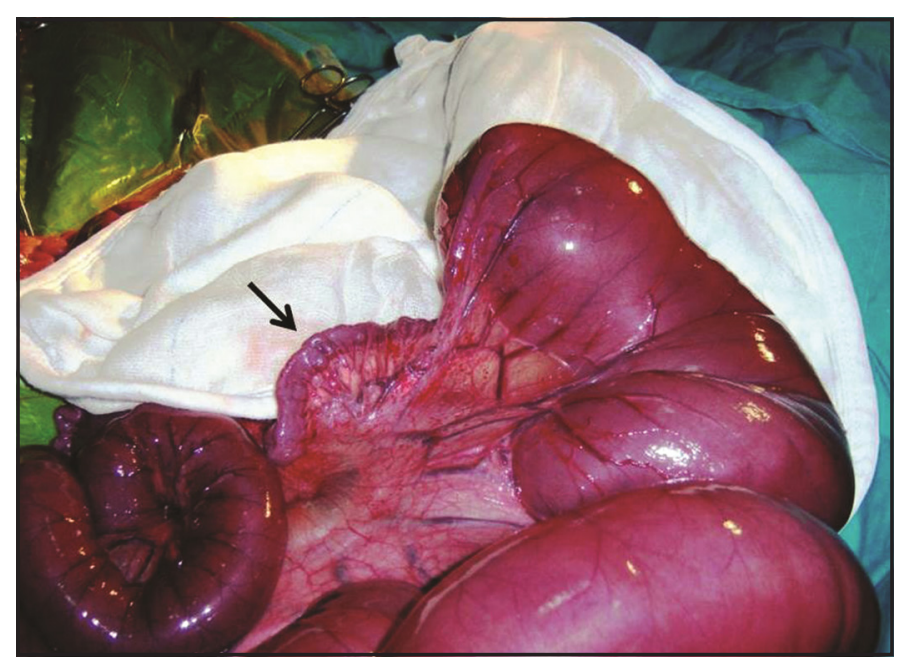

Figure 3. Intraoperative view of a case with type II atresia coli, the arrow demonstrates the atretic fibrous segment. 
H. Salci, S. Catik, E.S.O. Salci \& C. Ozakin. 2019. Peritoneal Fluid Analysis of the Newborn Calves with Intestinal Atresia - a Clinical Approach.

Table 1. Signalments, type of the atresia and post-diagnostic results (surgery, euthanized, died etc.) of the cases.

\begin{tabular}{|c|c|c|c|}
\hline Case & Signalments & Atresia & Result \\
\hline 1 & Holstein, $\partial^{\lambda}, 6$-day-old & Type III & colostomy \\
\hline 2 & Holstein, + , 1-day-old & Type IV & colostomy \\
\hline 3 & Holstein, $\hat{O}, 3$-day-old & Type III & colostomy \\
\hline 4 & Holstein, $\hat{\partial}, 2$-day-old & Type II & colostomy \\
\hline 5 & Holstein, $\widehat{O}, 2$-day-old & Type IV & colostomy \\
\hline 6 & Holstein, $\widehat{\jmath}, 3$-day-old & Type IV & colostomy \\
\hline 7 & Jersey,,+ , 7-day-old & Type II & colostomy \\
\hline 8 & Holstein, $\widehat{\partial}, 2$-day-old & Type II & colostomy \\
\hline 9 & Holstein, $\widehat{\jmath}, 2$-day-old & Type IV & colostomy \\
\hline 10 & Holstein, $\widehat{\partial}, 5$-day-old & Type III & postoperative died \\
\hline 11 & Holstein, + , 2-day-old & Type IV & preoperative died \\
\hline 12 & Holstein, q, 2-day-old & Type III & intraoperative died \\
\hline 13 & Holstein, + , 2-day-old & Type IV & colostomy \\
\hline 14 & Holstein, + , 4-day-old & Type II & preoperative died \\
\hline 15 & Holstein, $\widehat{\jmath}, 1$-day-old & Type II & euthanized \\
\hline 16 & Holstein,, , 2-day-old & Type IV & colostomy \\
\hline 17 & Holstein, ふ̃, 3-day-old & Type II & colostomy \\
\hline 18 & Holstein, $\widehat{\partial}, 2$-day-old & Type III & colostomy \\
\hline 19 & Holstein, $\widehat{\partial}, 3$-day-old & Type II & euthanized \\
\hline 20 & Holstein, ふ̂, 3-day-old & Type IV & euthanized \\
\hline 21 & Holstein, $\widehat{\jmath}, 10$-day-old & Type IV & euthanized \\
\hline 22 & Holstein, $\widehat{\partial}, 2$-day-old & Type II & colostomy \\
\hline
\end{tabular}

Table 2. Routine haematological results of the cases.

\begin{tabular}{cccccc}
\hline Case & $\begin{array}{c}\text { WBC } \\
\left(\mathrm{x} 10^{9} / \mathrm{L}\right)\end{array}$ & $\begin{array}{c}\text { Lym } \\
\left(\mathrm{x} 10^{9} / \mathrm{L}\right)\end{array}$ & $\begin{array}{c}\text { Mon } \\
\left(\mathrm{x} 10^{9} / \mathrm{L}\right)\end{array}$ & $\begin{array}{c}\text { Neu } \\
\left(\mathrm{x} 10^{9} / \mathrm{L}\right)\end{array}$ & $\begin{array}{c}\text { TP } \\
(\mathrm{g} / \mathrm{dL})\end{array}$ \\
\hline 1 & 11.6 & 4.83 & 1.04 & 7.77 & 9 \\
2 & 2.6 & 0.8 & 0.07 & 1.17 & 9 \\
3 & 12.3 & 3.56 & 0.98 & 7.74 & 6.9 \\
4 & 2.4 & 0.45 & 0.09 & 1.84 & 10.3 \\
5 & 23.5 & 4.23 & 2.35 & 16.45 & 6.9 \\
6 & 14.8 & 3.4 & 1.18 & 10.21 & 8.3 \\
7 & 8.0 & 3.2 & 0.24 & 4.56 & 8.8 \\
8 & 7.9 & 3.71 & 0.15 & 4.02 & 8.8 \\
9 & 8.3 & 2.32 & 0.41 & 5.56 & 7.6 \\
10 & 13.2 & 3.3 & 0.39 & 9.5 & 8.9 \\
11 & 18.0 & 4.68 & 0.1 & 12.24 & 7.8 \\
12 & 6.5 & 2.86 & 0.13 & 3.51 & 9.3 \\
13 & 11.4 & 1.93 & 0.34 & 9.12 & 6.9 \\
14 & 21.2 & 4.66 & 1.69 & 14.8 & 8.4 \\
15 & 15.2 & 4.4 & 0.91 & 9.88 & 8.9 \\
16 & 5.8 & 2.08 & 0.11 & 3.22 & 8.5 \\
17 & 11.7 & 3.27 & 0.7 & 7.72 & 7.6 \\
18 & 4.8 & 1.0 & 0.14 & 3.64 & 7.9 \\
19 & 8.6 & 3.09 & 0.51 & 4.98 & 10.3 \\
20 & 5.0 & 0.5 & 0.5 & 4.0 & 7.1 \\
21 & 44.13 & 13.23 & 0.44 & 30.44 & 5.9 \\
22 & 17.5 & 2.45 & 1.05 & 14 & 7.1 \\
\hline Ref & $4.0-12.0$ & $2.5-7.5$ & $0-0.9$ & $0.6-4.0$ & $6.3-8.9$ \\
\hline WBC: White blood cell; Lym: Lymphocyte; Mon: Monocyte; Neu: Neutrophil; TP: Total protein; Ref: Reference range.
\end{tabular}


H. Salci, S. Catik, E.S.O. Salci \& C. Ozakin. 2019. Peritoneal Fluid Analysis of the Newborn Calves with Intestinal Atresia - a Clinical Approach.

Acta Scientiae Veterinariae. 47: 1701.

Table 3. Peritoneal fluid analysis results of the cases.

\begin{tabular}{|c|c|c|c|c|c|c|c|c|c|c|c|}
\hline Case & $\begin{array}{l}\text { WBC } \\
\left(\mathrm{x} 10^{9}\right)\end{array}$ & $\begin{array}{l}\text { Lym } \\
\left(\mathrm{x} 10^{9}\right)\end{array}$ & $\begin{array}{l}\text { Mon } \\
\times 10^{9} / \mathrm{L}\end{array}$ & $\begin{array}{l}\text { Neu } \\
\left(\mathrm{x} 10^{9}\right)\end{array}$ & $\begin{array}{l}\mathrm{RBC} \\
\left(\mathrm{x} 10^{12}\right)\end{array}$ & $\begin{array}{l}\mathrm{Hgb} \\
(\mathrm{g} / \mathrm{dl})\end{array}$ & $\begin{array}{l}\text { Hct } \\
(\%)\end{array}$ & $\begin{array}{c}\mathrm{Plt} \\
\left(\mathrm{x} 10^{9}\right)\end{array}$ & $\begin{array}{c}\mathrm{TP} \\
(\mathrm{g} / \mathrm{dL})\end{array}$ & $\mathrm{D}$ & Microbiology \\
\hline 1 & 7.43 & 5.38 & 0.64 & 1.41 & 0.01 & 1.9 & 0.07 & 77 & 9.1 & 1052 & Escherichia coli \\
\hline 2 & 0.40 & 0.36 & 0.04 & 0.01 & 0.01 & 0.2 & 0.04 & 15 & 6.7 & 1046 & - \\
\hline 3 & 0.13 & - & - & - & - & 0.4 & - & 9 & 6.5 & 1040 & - \\
\hline 4 & 0.01 & - & - & - & 0.03 & - & 0.21 & 36 & 8.4 & 1055 & $\begin{array}{c}\text { Enterococcus casseliflavus/ } \\
\text { gallinarum, Staphylococcus } \\
\text { lugdunensis }\end{array}$ \\
\hline 5 & - & - & - & - & 0.02 & 0.3 & 0.13 & 67 & 4.1 & 1038 & Enterococcus faecium \\
\hline 6 & 0.18 & & & & 0.01 & 0.2 & 0.04 & 37 & 8 & 1042 & - \\
\hline 7 & 0.39 & 0.24 & 0.04 & 0.12 & - & 0.2 & - & 21 & 5.5 & 1038 & $\begin{array}{l}\text { Proteus vulgaris, } \\
\text { Citrobacter braakii }\end{array}$ \\
\hline 8 & 0.24 & - & - & - & 0.01 & 0.1 & 0.09 & 29 & 6.5 & 1041 & $\begin{array}{l}\text { Staphylococcus capitis ssp. } \\
\text { ureolyticus, Kocuria rosea }\end{array}$ \\
\hline 9 & 0.11 & - & - & - & - & 0.1 & - & 8 & 6.1 & 1039 & Escherichia coli \\
\hline 10 & 1.87 & 1.35 & 0.17 & 0.35 & 0.01 & 0.3 & 0.08 & 73 & 5.8 & 1041 & Escherichia coli \\
\hline 11 & 1.08 & 0.84 & 0.11 & 0.13 & 0.01 & 0.4 & 0.06 & 36 & 3.1 & 1034 & $\begin{array}{l}\text { Proteus spp., } \\
\text { Escherichia coli }\end{array}$ \\
\hline 12 & 0.22 & - & - & - & - & 0.9 & - & 33 & 7.2 & 1048 & Escherichia coli \\
\hline 13 & 0.68 & 0.52 & 0.06 & 0.10 & 0.02 & 2.2 & 0.10 & 93 & 6.8 & 1046 & - \\
\hline 14 & 0.11 & - & - & - & - & 0.1 & - & 17 & 7 & 1041 & - \\
\hline 15 & 0.17 & - & - & - & - & 0.1 & - & 12 & 7.8 & 1045 & - \\
\hline 16 & 0.02 & - & - & - & 0.02 & 0.2 & 0.10 & 29 & 7.7 & 1045 & - \\
\hline 17 & 0.25 & - & - & - & 0.01 & 0.1 & 0.06 & 32 & 4.9 & 1036 & $\begin{array}{l}\text { Proteus vulgaris, } \\
\text { Escherichia coli }\end{array}$ \\
\hline 18 & 0.37 & 0.27 & 0.03 & 0.07 & 0.01 & 0.2 & 0.07 & 20 & 6 & 1039 & Staphylococcus warneri \\
\hline 19 & 0.20 & - & - & - & 0.01 & 0.1 & - & 20 & 8 & 1046 & - \\
\hline 20 & 0.13 & - & - & - & 0.01 & 0.1 & 0.08 & 31 & 6.1 & 1040 & - \\
\hline 21 & 1.16 & 0.90 & 0.10 & 0.16 & 0.02 & 2.2 & 0.09 & 169 & 4.2 & 1032 & - \\
\hline 22 & 0.55 & 0.45 & 0.05 & 0.05 & 0.02 & 0.3 & 0.15 & 71 & 6.8 & 1040 & $\begin{array}{c}\text { Escherichia coli, Proteus } \\
\text { mirabilis }\end{array}$ \\
\hline Ref & $\begin{array}{c}0.3- \\
5.3\end{array}$ & 0.12 & 2.12 & $\begin{array}{l}0.12- \\
2.12\end{array}$ & - & - & - & - & $\begin{array}{c}0.1- \\
3.1\end{array}$ & $\begin{array}{l}1005- \\
1015\end{array}$ & - \\
\hline
\end{tabular}

WBC: White blood cell; Lym: Lymphocyte; Mon: Monocyte; Neu: Neutrophil; RBC: Red blood cell; Hgb: Hemoglobin; Hct: Hematocrit; Plt: Platelet; TP: Total protein; D: Density; Ref: Reference range.

Table 4. According to type of the intestinal atresia, the mean and standard deviation of haematological and peritoneal fluid analysis values and their comparative statistical results of the cases $(P<0.05)$.

\begin{tabular}{|c|c|c|c|c|c|c|}
\hline & Parameter & Tip II & Tip III & Tip IV & Ref & $P$ Values \\
\hline \multirow{5}{*}{ 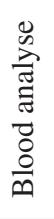 } & WBC $\left(\times 10^{9} / \mathrm{L}\right)$ & $11.56 \pm 6.09$ & $9.68 \pm 3.77$ & $14.83 \pm 12.87$ & $4.0-12.0$ & $P=0.583$ \\
\hline & $\operatorname{Lym}\left(x 10^{9} / \mathrm{L}\right)$ & $3.15 \pm 1.30$ & $3.11 \pm 1.38$ & $3.68 \pm 3.84$ & $2.5-7.5$ & $P=0.896$ \\
\hline & $\operatorname{Mon}\left(x 10^{9} / \mathrm{L}\right)$ & $0.66 \pm 0.54$ & $0.53 \pm 0.44$ & $0.61 \pm 0.73$ & $0-0.9$ & $P=0.932$ \\
\hline & $\mathrm{Neu}\left(\mathrm{x} 10^{9} / \mathrm{L}\right)$ & $7.72 \pm 4.78$ & $6.43 \pm 2.70$ & $10.26 \pm 8.97$ & $0.6-4.0$ & $P=0.549$ \\
\hline & TP (g/dL) & $8.77 \pm 1.13$ & $8.4 \pm 0.98$ & $7.55 \pm 0.96$ & $6.3-8.9$ & $P=0.70$ \\
\hline \multirow{10}{*}{ 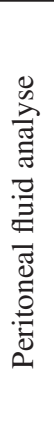 } & WBC $\left(\times 10^{9} / \mathrm{L}\right)$ & $0.24 \pm 0.16$ & $2.00 \pm 3.11$ & $0.41 \pm 0.45$ & $0.3-5.3$ & $P=0.105$ \\
\hline & $\operatorname{Lym}\left(x 10^{9} / \mathrm{L}\right)$ & $0.08 \pm 0.16$ & $1.4 \pm 2.29$ & $0.29 \pm 0.37$ & $0.12-2.12$ & $P=0.112$ \\
\hline & Mon $\left(x 10^{9} / \mathrm{L}\right)$ & $0.01 \pm 0.02$ & $0.16 \pm 0.27$ & $0.03 \pm 0.04$ & $0.12-2.12$ & $P=0.111$ \\
\hline & $\mathrm{Neu}\left(\mathrm{x} 10^{9} / \mathrm{L}\right)$ & $0.02 \pm 0.04$ & $0.36 \pm 0.60$ & $0.04 \pm 0.06$ & $0.12-2.12$ & $P=0.091$ \\
\hline & $\mathrm{RBC}\left(\mathrm{x} 10^{12}\right)$ & $0.01 \pm 0.01$ & $0.006 \pm 0.005$ & $0.01 \pm 0.007$ & - & $P=0.306$ \\
\hline & $\operatorname{Hgb}(\mathrm{g} / \mathrm{dL})$ & $0.12 \pm 0.08$ & $0.74 \pm 0.70$ & $0.65 \pm 0.88$ & - & $P=0.181$ \\
\hline & $\operatorname{Hct}(\%)$ & $0.06 \pm 0.08$ & $0.04 \pm 0.04$ & $0.07 \pm 0.03$ & - & $P=0.710$ \\
\hline & Plt $\left(\mathrm{x} 10^{9}\right)$ & $29.75 \pm 18.49$ & $42.4 \pm 30.98$ & $53.88 \pm 50.39$ & - & $P=0.430$ \\
\hline & $\mathrm{TP}(\mathrm{g} / \mathrm{dL})$ & $6.86 \pm 1.21$ & $6.92 \pm 1.33$ & $5.86 \pm 1.70$ & $0.1-3.1$ & $P=0.298$ \\
\hline & $\mathrm{D}$ & $1042 \pm 5.94$ & $1044 \pm 5.70$ & $1040 \pm 5.06$ & $1005-1015$ & $P=0.438$ \\
\hline
\end{tabular}

WBC: White blood cell, Lym: Lymphocyte, Mon: Monocyte, Neu: Neutrophil, RBC: Red blood cell, Hgb: Hemoglobin, Hct: Hematocrit, Plt: Platelet, TP: Total protein, D: Density, Ref: Reference range. 


\section{DISCUSSION}

Intestinal atresia is a congenital malformation of animals. In general, four types of intestinal atresia are encountered in calves [3,6,12], and all types are fatal pathologies; thus, surgery should urgently be planned as soon as diagnostic work-ups are completed after birth [6]. Peritoneal fluid analysis is a useful diagnostic choice because changes in the peritoneal fluid parameters help to diagnosis of the intra-abdominal pathology $[8,10,13,14]$. In the presented study, peritoneal fluid analysis were planned to evaluate the intra-abdominal pathological status of the calves with different type intestinal atresia.

In compatible with a pervious paper [3], which reports the intertinal atresia as more common anomaly in Holstein, Jersey and Montafon breed calves, in this study, intestinal atresia was diagnosed in 21 Holstein and 1 Jersey breed calves. Clinical findings such as abdominal distension, decreased appetite, progressive depression, signs of colic and failure of passing meconium indicated the presence of gastrointestinal obstruction in this study as reported previously $[1,6,12]$.

The age of the calf has never been associated with survival rate [12]. The calves classify clinically healthy or diseased based on the physical examination (body temperature, abdominal distension, abnormal vital signs or specific abnormalities) and diagnostic work-ups (radiology and ultrasonography) results $[1,6,14]$. The presented cases, in this study, were between 1 and 10 day-old, and all calves had abdominal distension and pain as well as inability of defecation. Abdominal radiographs showed the fluid and/or gasfilled intestinal segments and there were only craniocaudal fluctuating movements of the intestinal contents and gas-filling intestinal segments causing the artifacts in the ultrasonographic examination.

In animals with intestinal atresia, surgical treatment is not usually recommended due to economic reasons and small chance of postoperative success [1]. Long-term survival rate of surgically treated animals depends on the type of intestinal atresia and applied surgical technique [6,12]. Atresia recti and ani may occur simultaneously with atresia coli [12], and all atresias (atresia coli, ani, recti or ani et recti) can be successfully treated by surgery [3]. According to our results, we diagnosed type II $(\mathrm{n}=8)$, type III $(\mathrm{n}=5)$ and type IV $(n=9)$ intestinal atresia both during surgical intervention and at necropsy. Surgery (anastomosis of the intestinal segments or colostomy) should be considered urgently, because continuous distention of the large intestinal segments leads to ischemia, necrosis, peritonitis and bowel perforation $[3,6,12]$. In the presented study, follow-up cares after surgery was made and the calves were discharged without any complication. Early stage postoperative results were informed by the owners that all operated calves was healthy. However, four calves were euthanized due to their owners' request, two calves had poor condition, and one calf died intraoperatively. Most common complications after surgery in intestinal atresia were peritonitis, failure of anastomosis, diarrhoea, impaction of the anastomosis site, incisional infection, chronic cecal dilatation, functional obstruction of the spiral colon and adhesive bowel obstruction [3,6]. In this study, colostomy site dehiscence was an encountered mortal complication following to surgery.

The appearance of normal peritoneal fluid in calves is slightly cloudy [5,9] and its color varies from pale yellow to pale red $[5,10]$. In this study, physical appearances of the peritoneal fluid were yellowish and had mild to moderate cloudy appearance. Although there was no bloody appearance, they had fibrin formation. In the reported studies [5,9,10,14], investigations are focusing on both peritoneal fluid and blood analysis in animals. Analyses usually target to determine color, turbidity, D, TP and WBC for the classic transudate-exudate categorization $[8,13,14]$. Peritoneal fluid analysis should include the classic parameters for diagnosis, but these analyses are often insufficient to identify the etiology or pathogenesis of the disease [15]. An increase in total WBC count and percentage of the neutrophil cells in the peritoneal fluid indicate the acute infectious origin inflammation $[8,10,11,13]$. In the presented study, septic peritonitis was determined in case 1 due to high WBC value in peritoneal fluids. High levels of TP and D in all cases pointed out the signs of the severe inflammation as determined previously $[8,15]$. Routine hematological analysis was made to evaluate the health conditions of the calves before surgery. The combination of high WBC (9 / 22 calves) and neutrophil counts (16 / 22 calves) and increased TP values (5/ 22 calves) showed acute inflammation in these calves. Leukopenia was only observed in 2 calves that it was due to septicemia in these calves. In addition, the mean and standard deviations of the parameters, considering to types of the 
intestinal atresia, were about within normal reference ranges except TP and $\mathrm{D}$, and statistical comparison of these parameters revealed no significant difference between the types of the intestinal atresia. The RBC is considered as contamination from the peripheral blood during sampling, but it has not been frequent variable evaluated in the peritoneal fluids [8-10]. RBC, Hgb, Hct and Plt were encountered in the peritoneal fluid analysis of the cases, which were considered blood contamination during sampling.

Additional parameters in the peritoneal fluid analysis have been established to improve diagnostic precision and specific information $[8,14,15]$. The reported parameters are lactate dehydrogenase, fibrinogen, C-reactive protein, cytokines, L-lactate, Ddimer, inorganic phosphate that they may indicate the bacterial infections and intestinal ischemic conditions $[9,14,15]$. The routine serobiochemical parameters and microbiological culture results of peritoneal fluid analysis was evaluated in this study. It is our limitations that some other analysis should be planned to adequate much more exact information to assess the intra-abdominal situations of the calves with different type intestinal atresia.

Presence or absence of the bacteria in the peritoneal fluid samples is important to characterize the transudate and exudate $[4,8,14]$. Microbiological culture of the peritoneal fluid samples may result in presence of bacteria, which is an indicator for infective peritonitis $[4,8,10,11,14]$. Bacteria may arise by hematogenous spread from intestinal lumen into the systemic and peripheral blood stream $[4,10]$. Translocation of bacteria and their toxins play a decisive role in development of systemic septic complications. The principal causes of bacterial translocation are disorders of the physical and physiological functions of the intestinal mucosal barriers [4]. In the presented study, fecal origin bacteria were obtained in the peritoneal fluid culture results of 12 cases. Considering to microbiological culture results, it might be concluded that there was no differentiation between the types of the intestinal atresia and these cases had infective peritonitis. Gram-negative bacteria predominate in septic peritonitis. Escherichia coli is the most common isolated microorganism that it is usually found in $57-74 \%$ of cultures from the peritoneal cavity [7]. We agree with this literature data because E. coli was the most common bacteria in the microbiological culture results of the peritoneal fluid samples in calves. Antibiotic usage is mandatory [7], and selection of the antibiotic regimen should be planned after diagnosis of the septic peritonitis, and culture and susceptibility test results of the peritoneal fluid [7,11]. In general, penicillin or cephalosporin and their combinations may be choice until culture or susceptibility data become available [7]. Following clinical diagnosis, a routine antibiotic agent was administered and repeated in the postoperative period considering to culture results of the peritoneal fluids in the calves.

\section{CONCLUSION}

It may be emphasized that peritoneal fluid analysis contributes the evaluation of the healthy status in the calves with intestinal atresia. However, changings in the peritoneal fluid values does not related to type of the intestinal atresia.

\section{MANUFACTURERS}

${ }^{1}$ Ilgi Medikal. Bursa, Turkey.

${ }^{2}$ Abaxis Europe GmbH. Darmstadt, Germany.

${ }^{3}$ Atago USA Inc. Bellevue, WA, USA.

${ }^{4}$ Becton Dickinson. Heidelberg, Germany.

${ }^{5}$ Becton Dickinson. Sparks, MD, USA.

${ }^{6}$ Egevet. Izmir, Turkey.

${ }^{7}$ Alke. Istanbul, Turkey.

${ }^{8}$ Topkim. Istanbul, Turkey.

${ }^{9}$ IBM. Austin, TX, USA.

Declaration of interest. The authors report no conflict of interest, and the authors alone are responsible for the content and writing of the paper.

\section{REFERENCES}

1 Abouelnasr K., Ishii M., Inokuma H., Kobayashi Y., Lee K. \& Yamada K. 2012. Atresia coli in a Japanese black calf diagnosed by a barium sulphate enema contrast radiograph in the standing position: a case report. Veterinary Medicine. 57(7): 376-379.

2 Alacam E. 2010. Evcil Hayvanlarda Doğum ve Infertilite. Ankara: Medisan, pp.123-129.

3 Atalan G., Ozaydin I., Kilic E., Cihan M. \& Kamiloglu A. 2003. Buzağılarda intestinal atresia olguları ve operatif sağaltımları: 54 olgu (1992-2000). Kafkas Universitesi Veteriner Fakultesi Dergisi. 9(2): 113-118. 
4 Belyansky L.S., Sayenko V.F., Furmanov J.A. \& Churilova T.J. 2002. Bacterial translocation as a cause for septic complications in obstructive colonic ileus. Acta Chirurgica Belgica. 102: 75-77.

5 Burton S., Lofstedt J., Webster S. \& McConkey S. 1997. Peritoneal fluid values and collection technique in young, normal calves. Veterinary Clinical Pathology. 26(1): 38-44.

6 Cecen G., Salci H., Caliskan G.U., Celimli N., Seyrek-Intas D. \& Gorgul O.S. 2010. Modified colostomy technique for colonic atresia in calves. Veterinary Surgery. 39: 722-728.

7 Culp W.T.N. \& Holt D.E. 2010. Septic peritonitis. Compendium on Continuing Education for the Practicing Veterinarian. 32(10): E1-E15.

8 Hirsch V.M. \& Townsend H.G.G. 1982. Peritoneal fluid analysis in the diagnosis of abdominal disorders in cattle: a retrospective study. Canadian Veterinary Journal. 23: 348-354.

9 Mendes L.C.N., Peiro J.R., Feitosa F.L.F., Luvizotto M.C.R., Borges A.S., Ciarlini P.C. \& Perri S.H.V. 2005. Effect of age and abomasal puncture on peritoneal fluid, hematology, and serum biochemical analyses in young calves. Journal of Veterinary Internal Medicine. 19: 899-904.

10 Radostits O.M., Gay C.C., Hinchcliff K.W. \& Constable P.D. 2006. Veterinary Medicine. Philadelphia: Saunders Elsevier, pp.199-203.

11 Ragetly G.R., Bennett R.A. \& Ragetly C.A. 2011. Septic peritonitis: treatment and prognosis. Compendium on Continuing Education for the Practicing Veterinarian. 33(10): E1-E6.

12 Suresh Kumar R.V., Veena P., Sankar P., Dhana Lakshmi N.D. \& Kokila S. 2011. Surgical management of atresia recti-ani and coli in a Holstein Friesian Cross bred calf. Veterinary World. 4(4): 176-177.

13 Wilson A.D., Hirsch V.M. \& Osborne A.D. 1985. Abdominocentesis in cattle: technique and criteria for diagnosis of peritonitis. Canadian Veterinary Journal. 26: 74-80.

14 Wittek T., Grosche A., Locher L.F., Alkaassem A. \& Fürll M. 2010. Biochemical constituents of peritoneal fluid in cows. Veterinary Record. 166: 15-19.

15 Wittek T., Grosche A., Locher L.F. \& Fürll M. 2010. Diagnostic accuracy of D-dimer and other peritoneal fluid analysis measurements in dairy cows with peritonitis. Journal of Veterinary Internal Medicine. 24(5): 1211-1217. 